\title{
Schneede, Uwe M., Max Beckmann : der Maler seiner
}

Zeit

Jeanne-Marie Portevin

\section{OpenEdition}

Journals

Édition électronique

URL : http://journals.openedition.org/ifha/6705

DOI : 10.4000/ifha.6705

ISSN : 2198-8943

Éditeur

IFRA - Institut franco-allemand (sciences historiques et sociales)

Référence électronique

Jeanne-Marie Portevin, «Schneede, Uwe M., Max Beckmann : der Maler seiner Zeit », Revue de l'IFHA [En ligne], Date de recension, mis en ligne le 01 janvier 2011, consulté le 22 septembre 2020. URL : http:// journals.openedition.org/ifha/6705; DOI : https://doi.org/10.4000/ifha.6705

Ce document a été généré automatiquement le 22 septembre 2020

(CIFHA 


\title{
Schneede, Uwe M., Max Beckmann : der Maler seiner Zeit
}

\author{
Jeanne-Marie Portevin
}

1 Max Beckmann : le peintre de son temps. C'est ainsi qu'U.M.S. intitule l'ouvrage qu'il consacre à l'un des artistes majeurs des avant-gardes historiques allemandes. Tout au long d'un texte de 302 pages richement illustré, le vénérable spécialiste de l'art allemand du XXe siècle déroule un fil rouge qui révèle les œuvres du peintre comme autant de représentations d'une époque traversée par deux guerres mondiales, la naissance chaotique d'une République, une crise économique internationale, la montée et l'épanouissement des fascismes.

2 Ce peintre, né en 1884 à Leipzig, fait très jeune une entrée remarquée sur la scène artistique allemande. Ses œuvres accompagnent la naissance de l'expressionnisme, puis de la " Nouvelle Objectivité » après la Première Guerre mondiale, sans toutefois s'y confondre totalement. Jusqu'en 1937, année de son exil aux Pays-Bas, après quatre ans de dictature hitlérienne, Beckmann, consacré comme le plus allemand de tous les peintres allemands, connaît un succès toujours grandissant. Si la critique l'encense et le public le suit, ce succès est aussi le fruit d'un plan mûrement réfléchi. C'est l'un des intérêts du livre d'U.M.S. qui, contrairement à de nombreux auteurs encore aujourd'hui, n'hésite pas à observer le parcours du peintre en ce qu'il recèle de stratégies de carrière, renonçant à la vision candide et dépassée d'un artiste bohème détaché de toutes les contingences matérielles. Se dessine l'image d'un producteur exigeant et conscient du marché.

3 Le livre suit le modèle classique de la monographie, cet exercice obligé de l'histoire de l'art depuis Vasari. Il adopte un découpage chronologique et propose des illustrations assorties de commentaires, proposant de la sorte deux niveaux de lecture, l'un pour le lecteur pressé, l'autre pour l'amateur en quête de savoir exhaustif. Si l'on apprécie le ton simple et pédagogique de l'auteur, on peut lui reprocher quelques simplifications rapides et grossières tant sur la vie que sur l'œuvre du peintre allemand. Ainsi lorsqu'il évoque le conflit entre les sexes comme l'un des thèmes majeurs de l'œuvre de Beckmann, on peut regretter qu'il ne replace ledit conflit dans le contexte historique et 
social et ne mentionne aucun des artistes de la même génération - on pense en particulier à Anton Räderscheidt - qui se sont également intéressés à ce motif. De même, lorsqu'il aborde les tableaux religieux que Beckmann peint au sortir de la Première Guerre mondiale, il omet d'indiquer qu'ils font partie d'un vaste ensemble d'œuvres d'artistes divers qui utilisent la figure du Christ crucifié pour évoquer le martyre des soldats dans la guerre des tranchées. U.M.S. tombe ici finalement dans le piège qui attend tout auteur de monographie, celui qui fait oublier au spécialiste de chausser d'autres lunettes que celles de son sujet, de regarder avec d'autres yeux. L'empathie, si elle permet parfois la compréhension de certaines clés autobiographiques contenues dans les œuvres, ne doit pas conduire à gommer les côtés sombres de toute personnalité et à en réviser la biographie. Ainsi, aveuglé par la fascination qu'exerce sur lui son sujet, il ne voit dans l'art et la vie de Beckmann durant la période nazie qu'actes de résistance. Alors que Jonathan Petropoulos avait signalé, dans un ouvrage paru en 1996 (Art as Politics in the Third Reich), la présence de Beckmann à une réception somptueuse offerte par les Ribbentrop le 11 août 1936, U.M.S. relate à peine, si ce n'est pas du tout, les efforts que fournit le peintre pour continuer de vendre ses tableaux et faire accepter sa peinture par les nazis.

Reste que cette publication constitue une étude précieuse pour la compréhension de l'œuvre de Beckmann, en particulier par le travail minutieux qu'il a effectué à partir des sources primaires, comme la correspondance et les journaux de l'artiste, ainsi que les notes laissées par Mathilde Beckmann.

Jeanne-Marie Portevin (université Paris I) 